\title{
Medical Image of the Week: Evolution of Low Grade Adenocarcinoma
}

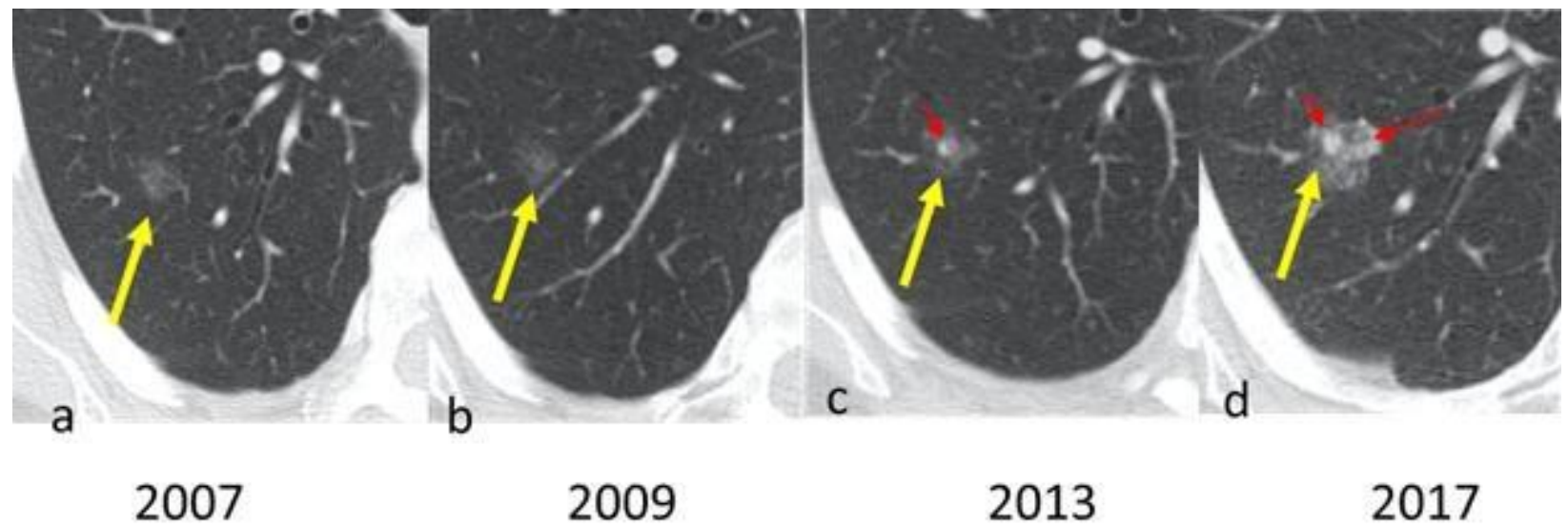

Figure 1. Coned down chest CT images. Panels a-d: small ground glass focus in the right upper lobe demonstrating slow growth over a period of 10 years (yellow arrows) and gradual development of a soft tissue component (red arrows).

Ground glass lesions above $5 \mathrm{~mm}$ in greatest diameter found on chest computed tomography (CT) require initial followed up in 3 months according to the Fleischner Society Guidelines, to exclude a transient inflammatory focus (1). If persistent, surveillance for at least 24 months to confirm stability is recommended. Any change in size or density should warrant further action, ideally surgical consultation, given the suboptimal yield of percutaneous biopsy and risk of inappropriate staging if the whole lesion is not examined. This may result in the inability to recognize the transition from insitu adenocarcinoma into minimally invasive or invasive lesions, which in turn results in inaccurate staging and prognosis.

Diana Palacio MD, Berndt Schmit MD, and Veronica Arteaga MD

Department of Medical Imaging

Banner-University Medical Center Tucson

Tucson, AZ USA

\section{Reference}

1. MacMahon H, Austin JH, Gamsu G, Herold CJ, Jett JR, Naidich DP, Patz EF Jr, Swensen SJ; Fleischner Society. Guidelines for management of small pulmonary nodules detected on CT scans: a statement from the Fleischner Society. Radiology. 2005 Nov;237(2):395-400. [CrossRef] [PubMed] 